\title{
EDITORIAL
}

\section{LA ATENCIÓN FARMACÉUTICA}

Hace veinte años, en el Congreso de educación farmacéutica realizado en la Universidad de Minneapolis en los Estados Unidos, el entonces presidente de la Asociación Americana de Farmacéuticos de Hospital, Dr. Donald Francke, a quién se considera el padre de la Farmacia Clínica, en su discurso de inauguración del evento dijo: "Entre los profesionales del área de salud, el farmacéutico es el menos conocido y el peor utilizado". Esto lo dijo refiriéndose a que el ejercicio profesional del farmacéutico de ese entonces, no correspondía a la preparación recibida durante el ciclo profesional, ya que no tenía oportunidad de aplicar esos conocimientos en su práctica ordinaria. Desde ese entonces, se han producido muchos cambios, han surgido nuevas modalidades de ejercicio profesional, las que han dado lugar a que se creen programas de educación continua y se ofrezcan áreas de especialización. De otro lado, las instituciones educacionales, así como los colegios profesionales, están trabajando para dar respuesta a lo enunciado por la Organización Mundial de la Salud (OMS) cuando preconiza que: "el uso racional de los medicamentos supone que los pacientes reciban los medicamentos adecuados a sus necesidades clinicas, en las dosis precisas, según sus requerimientos individuales, durante un tiempo prescrito y al menor costo posible para los pacientes y la comunidad". Dando cumplimiento a estos postulados de la OMS, ha surgido la Atención Farmacéutica que representa una respuesta al reto de mejorar el acto farmacéutico de acuerdo a las directrices del Organismo Internacional de Salud.

Son numerosos los objetivos concretos que pueden enumerarse para describir lo que es la Atención Farmacéutica, sin embargo en forma muy resumida podemos enumerar tres grandes areas: (a) la Dispensación (b) la Consulta o entrevista con el farmacéutico y (c) el Seguimiento. O sea la observación del perfil medicamentoso del paciente.

El primero, es decir la dispensación, consiste en la entrega del preparado o producto farmacéutico en las mejores condiciones y de acuerdo a las normas legales vigentes, y luego proteger o prevenir al paciente de los posibles problemas relacionados con el medicamento. En lo referente a la consulta o entrevista con el farmacéutico, esta 
tiene por objeto indicar al paciente la actitud más adecuada a su problema de salud, resolver sus dudas o carencias de información, y evaluar los problemas que pudieran surgir como consecuencia del medicamento que ésta tomando.

Por su parte, el seguimiento farmacéutico, busca la obtención de la máxima efectividad del tratamiento farmacológico, minimizando los riesgos asociados al empleo de los medicamentos, por tanto busca mejorar la seguridad de la terapia, así como el contribuir a la racionalización del uso de los medicamentos y contribuir a mejorar la calidad de vida del paciente.

En forma resumida, podemos decir que la Atención Farmacéutica consiste básicamente, en considerar al paciente como eje de la actuación profesional, controlando el tratamiento prescrito, vigilando su cumplimiento, comprometiéndose con los resultados obtenidos y registrando todo el proceso.

Con la Atención Farmacéutica, el medicamento deja de ser un fin en sí mismo, para convertirse en un medio para conseguir los objetivos terapéuticos previstos y deseados.

Para dar cumplimiento a todos esos objetivos, el farmacéutico requiere modificar actitudes, métodos y medios que demanden que esté al corriente de los progresos y cambios constantes que se producen en los conocimientos referentes al medicamento, la terapia y la salud, es decir que parte de su ejercicio debe estar dedicado a la formación continuada de la que actualmente existen variados programas a nivel de postgrado en todas las Facultades de Farmacia. 